\title{
A Prediction Model for Taiwan Tourism Industry Stock Index
}

\author{
Han-Chen Huang and Fang-Wei Chang \\ Yu Da University of Science and Technology, Taiwan
}

\begin{abstract}
Investors and scholars pay continuous attention to the stock market, as each day, many investors attempt to use different methods to predict stock price trends. However, as stock price is affected by economy, politics, domestic and foreign situations, emergency, human factor, and other unknown factors, it is difficult to establish an accurate prediction model. This study used a back-propagation neural network (BPN) as the research approach, and input 29 variables, such as international exchange rate, indices of international stock markets, Taiwan stock market analysis indicators, and overall economic indicators, to predict Taiwan's monthly tourism industry stock index. The empirical findings show that the BPN prediction model has better predictive accuracy, Absolute Relative Error is 0.090058, and correlation coefficient is 0.944263. The model has low error and high correlation, and can serve as reference for investors and relevant industries.
\end{abstract}

\section{KEYWORDS}

Artificial Neural Network, Stock Market Analysis, Prediction Model

\section{INTRODUCTION}

Investors aim to reduce risk and obtain high returns in stock investment; however, there are many factors affecting stock market changes. Prediction of stock market change is difficult and complicated; the previous studies have conducted fundamental analysis [1,2] and technical analysis $[3,4]$ to predict stock change. Nowadays, with advancements of technologies, and improvement of computer algorithm performance, Artificial Neural Network (ANN) is derived to deal with complicated and mass stock prediction problems. The relevant research findings have demonstrated that ANN has good accuracy and reliability in stock market prediction.

ANN is a type of artificial intelligence. Due to better fault tolerance, it is able to accurately predict results even if some noise occurs. Thus, many researches use ANN to predict changes of stock indices. This study uses BPN to establish a model for prediction of Taiwan's monthly tourism industry stock indices. The international exchange rate, international stock indices, Taiwan stock analysis indicator, and overall economic index, are input variables to improve the accuracy of the prediction model [5-8].

\section{RESEARCH METHOD}

ANN is an information processing system that simulates brain and neural networks, and can store, learn, and recall external input signals. ANN is a computing system involving software and hardware, which uses a mass of interconnected artificial nerve cells to simulate neural networks. It obtains and calculates information from external environments or other nerve cells, and sends the results to external environments or other nerve cells [5-8].

DOI : 10.5121/ijcsit.2013.5609 
In this study, the proposed ANN is divided into three parts: process element, layers, and network, as shown in Figure 1 [9-14].

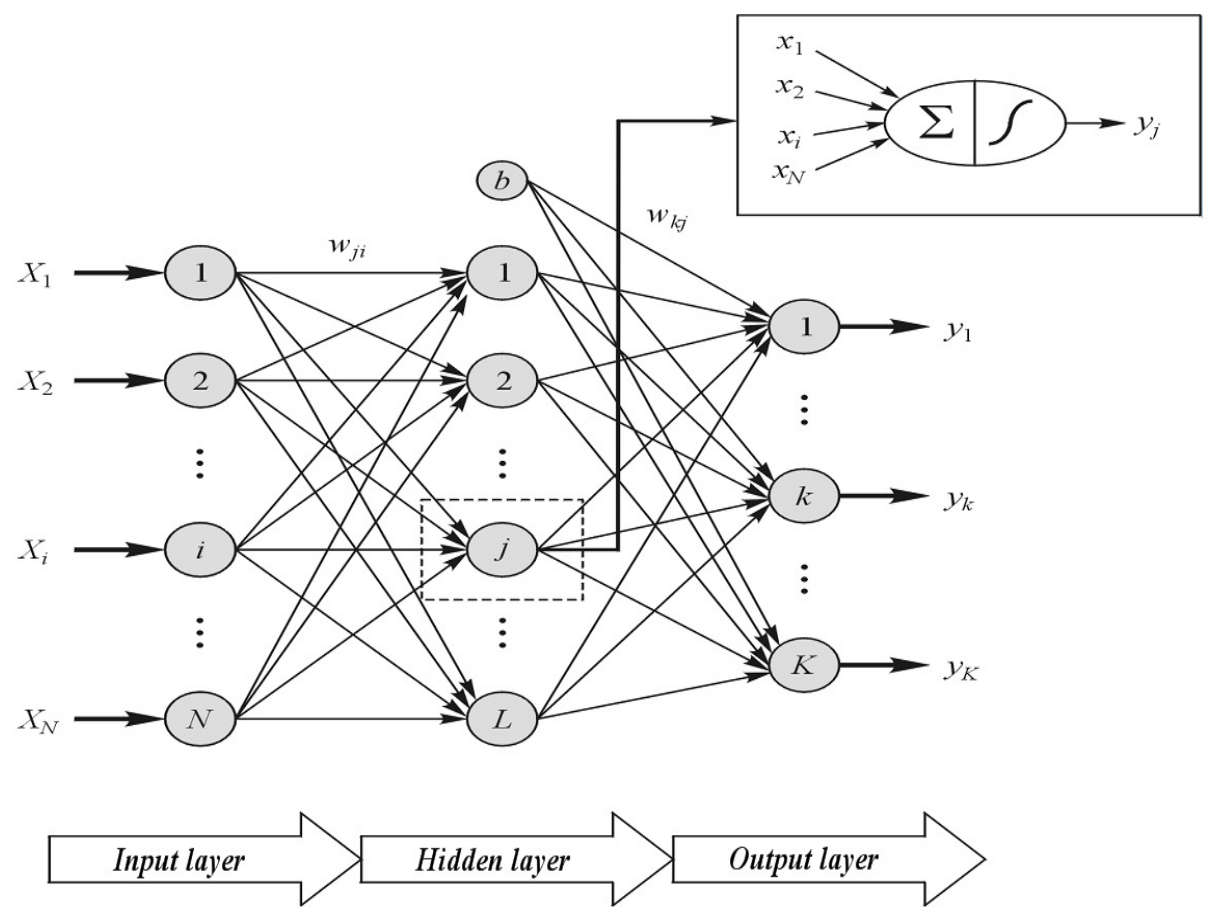

Figure 1. Three-layer network model architecture [11-14]

(1) Process element: artificial neurons are called nerve cells, artificial nerve cells, or process element. Each type of nerve cells are sent in the shape of a fan, and become the input of other types of nerve cells. The relationship between input and output values of each element can be expressed by the weighted product of input value and function.

(2) Layer: the part consisting of several process elements with the same functions is called a layer. The artificial neural network contains three layers: input layer, hidden layer, and output layer.

(3) Network: the architecture consisting of different layers is network connection. Layers are bonded through neurons to form the entire network connection. It has two functions of learning and recall.

\subsection{ANN operation steps}

Step 1: Analyze-International exchange rate, international stock markets (Dow Jones index, Nasdaq index, ICIW 225 and Shanghai composite index), technical analysis of Taiwan stock market (MA5, MA10, MA20, K9, D9, BIAS5, BIAS10, BIAS20, RSI5, RSI14, MACD, and OSC), and overall economy (consumer price index, Taiwan's GDP, cyclical indicators, industrial production index, expected rate of inflation, score of business cycle indicators), are used as input variables to predict Taiwan's monthly tourism industry indices: the data between November 2003 and May 2013 were selected, for a total of 127 data; where $70 \%$ of data are used for model training, $15 \%$ for model verification, and $15 \%$ for model testing.

Step 2: Preprocess-The image range of input variables is set to intervals $[-1,+1]$, and $[0,1]$, and variable data are normalized. 
Step 3: Network architecture design: automatic search function is used to select the optimal network architecture. The optimal network architecture is 29-71-1 (Figure 2); the Input layer has 29 neurons, the hidden layer has one layer with 71 neurons, and the output layer has one neuron.

Step 4: Network training and verification: quick propagation is used. The quick propagation coefficient is set to 10 , and the learning rate is set to 0.2 . The limit for number of iterations is set to 2000 times for network training (Figure 3).

\begin{tabular}{|c|c|c|c|c|c|c|c|c|c|}
\hline ID & |Architecture & $\#$ of W & "Fithess & Testerror & Akakike's citt & ion $\mid R$-Squared & Correation & Train Error & Sttop Reason \\
\hline 12 & [29-71-1] & 2202 & 0.13211 & 7.569426 & 0.000241 & 0.975494 & 0.987728 & 3.845507 & All iterations done \\
\hline 8 & {$[29-70-1]$} & 2171 & 0.128666 & 7.772035 & 0.000243 & 0.968631 & 0.98445 & 4.696317 & All iterations done \\
\hline 3 & [29-62-1] & 1923 & 0.1113331 & 8.823708 & 0.000275 & 0.95008 & 0.974998 & 5.811271 & All iterations done \\
\hline 4 & [29-38-1] & 1179 & 0.109964 & 9.093884 & 0.000464 & 0.937209 & 0.968158 & 6.612603 & All iterations done \\
\hline 2 & [29-100-1] & 3101 & 0.101315 & 9.870212 & 0.000167 & 0.943399 & 0.972534 & 6.221454 & All iterations done \\
\hline 5 & [29-85-1] & 2636 & 0,100433 & 9.956928 & 0.000197 & 0,900267 & 0,949229 & 8.303599 & All iterations done \\
\hline 11 & [29-68-1] & 2109 & 0.099995 & 10,000518 & 0.000248 & 0,902206 & 0,950218 & 8.088917 & All iterations done \\
\hline 6 & {$[29-52-1]$} & 1613 & 0,098669 & 10,134945 & 0.000329 & $\omega^{3} 0,901969$ & 0,949901 & 8.32012 & All iterations done \\
\hline 13 & {$[29-72 \cdot 1]$} & 2233 & 0.092059 & 10.862589 & 0.000233 & 0.8956 & 0.949397 & 8.4333126 & All iterations done \\
\hline 7 & {$[29-76-1]$} & 2357 & 0.091894 & 10.882113 & 0.000221 & 0.900349 & 0,951902 & 8.427195 & All tierations done \\
\hline 9 & [29-66-1] & 2047 & 0,090738 & 11.020759 & 0.000265 & 0.995299 & 0,997691 & 1.525125 & All iterations done \\
\hline 10 & {$[29-73-1]$} & 2264 & 0.087939 & 11.371469 & 0.00023 & 0.883723 & 0.940947 & 8.824916 & All iterations done \\
\hline 1 & [29-1:1] & 32 & 0,058021 & 17,234997 & $-0,013964$ & 0.67355 & 0.882362 & 15,183782 & All iterations done \\
\hline
\end{tabular}

Figure 2. The result of optimal network architecture

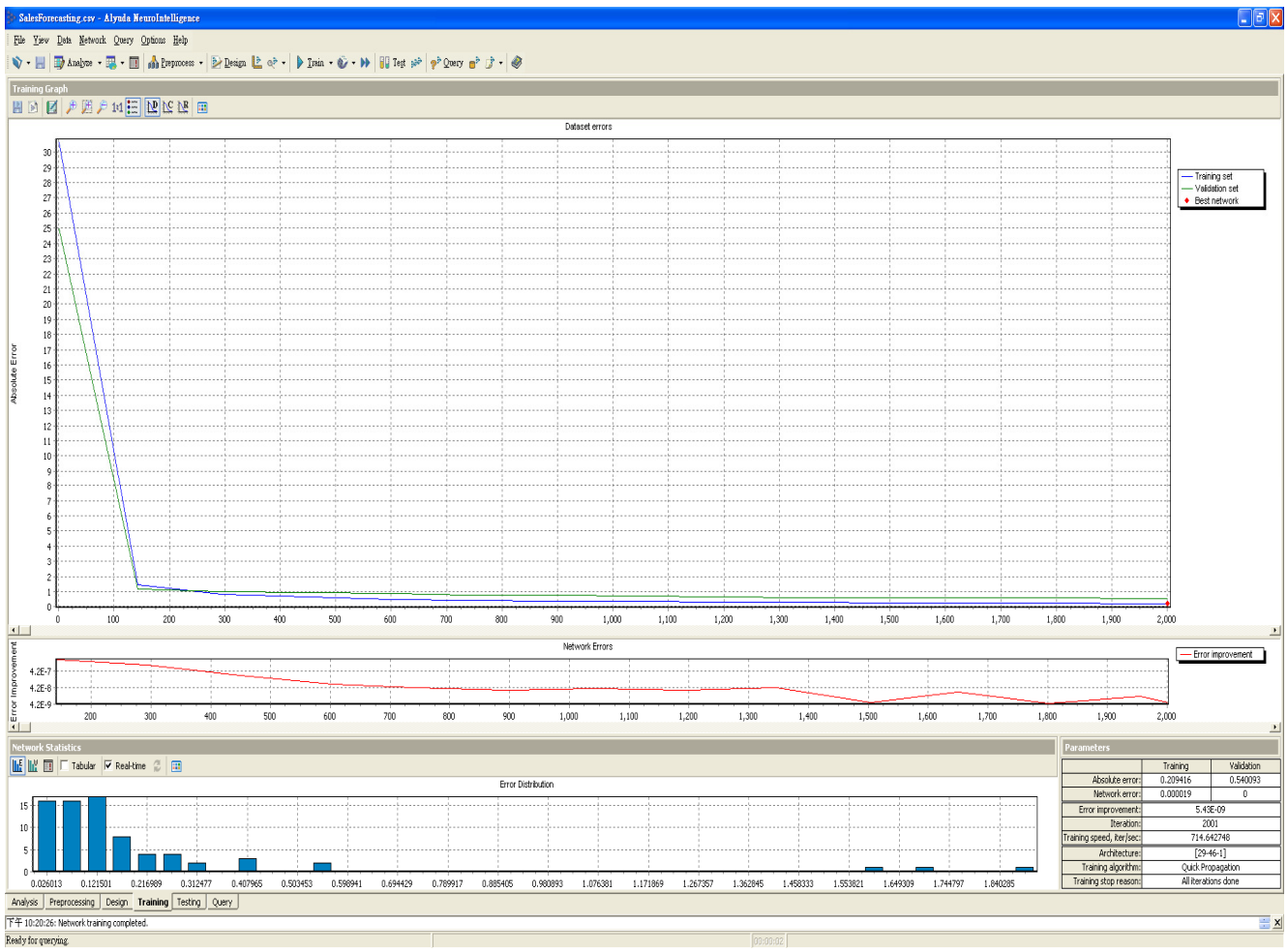

Figure 3. Absolute error of iterative convergence 


\subsection{Evaluation criterion}

In this study, three indices are used to evaluate the accuracy of the proposed model:

- $\mathrm{AE}$ (absolute error) is the difference between the measured value and true value.

- ARE (absolute relative error) is expressed as a percentage ratio of absolute error to true value, and can reflect the confidence level of data. The smaller the value, the higher the confidence level.

- $r$ (correlation coefficient), when $r$ is close to 1 , the actual value is highly related to the predicted value, and when $r$ is close to 0 , the actual value is less related to the predicted value.

\section{RESUlts OF EMPIRICAL ANALYSIS}

In this study, the 29 input variables, including international exchange rate, indices of international stock markets, indicators of Taiwan stock market analysis, and overall economic indicator, are used to predict the monthly tourism industry stock index. The results of model training are as shown in Table 1. The output value and actual value of the model are ARE $=1.8611 \%$ and $\mathrm{r}=$ 0.996878 , indicating the trained model has low error and high correlation. Figures 4 and 5 are the trend chart and scatter diagram of the model input value and actual value. It can be found that the input value can reflect the fluctuation of actual value, and has high correlation.

Table 1. Results from model training

\begin{tabular}{|c|c|c|c|c|}
\hline & Target & Output & AE & ARE \\
\hline Mean & 106.299136 & 106.22766 & 1.758696 & 0.018611 \\
\hline Std Dev & 32.807466 & 32.486709 & 1.915795 & 0.020894 \\
\hline \multicolumn{5}{|c|}{ Correlation: 0.996878} \\
\hline
\end{tabular}

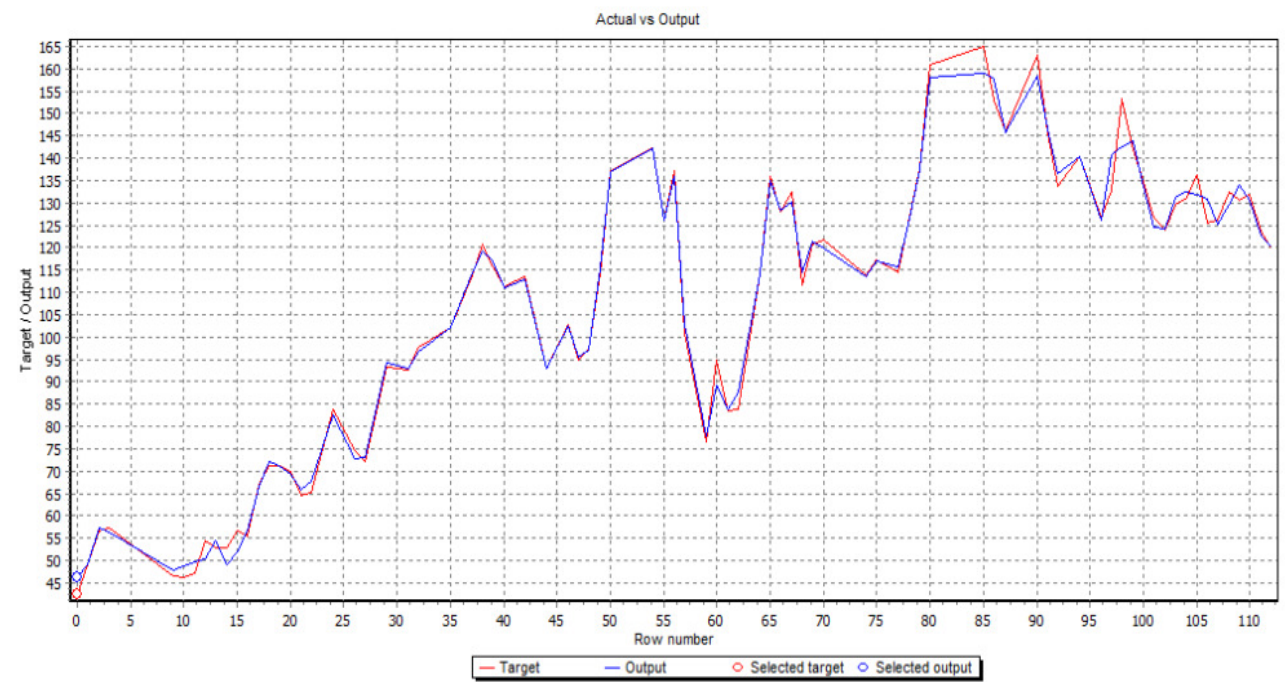

Figure 4. Trend chart of model training 


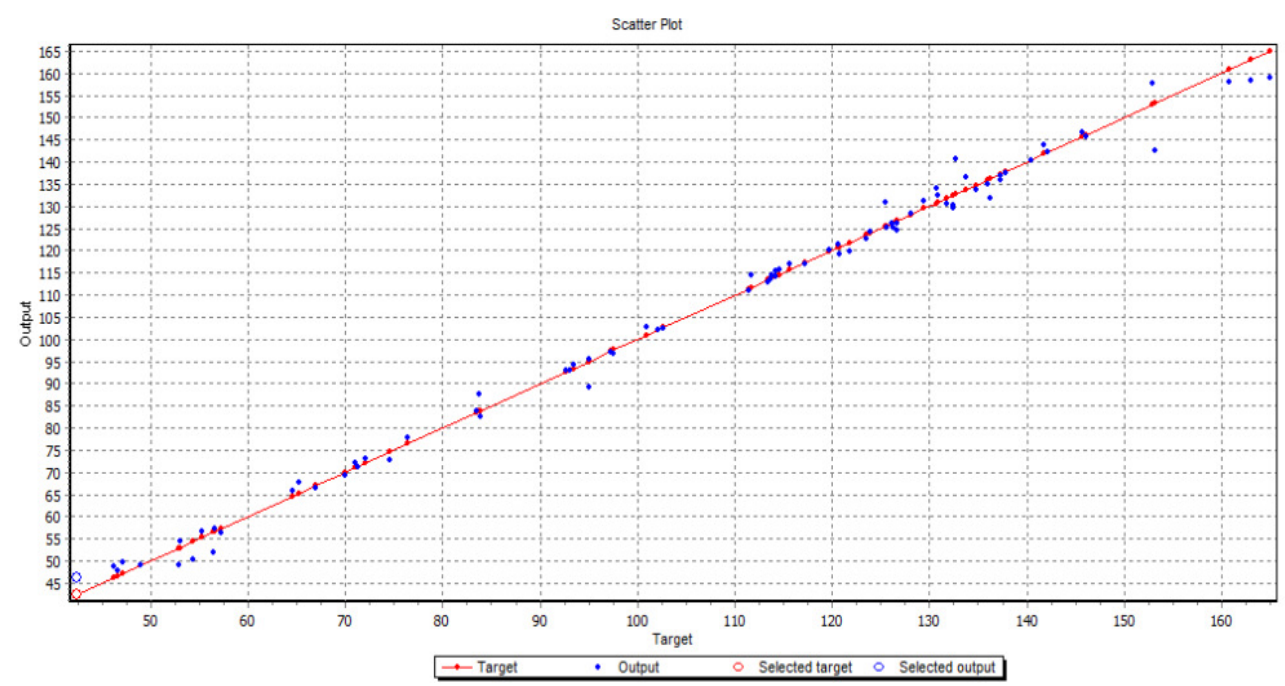

Figure 5. Scatter diagram of model training

The results of model verification are as shown in Table 2 . The output value and actual value of the model are $\mathrm{ARE}=6.8242 \%$ and $\mathrm{r}=0.996878$, indicating the model has low error and high correlation. Figures 6 and 7 are the trend chart and scatter diagram of the model input value and actual value. It can be found that the input value can reflect the fluctuation of actual value, and has high correlation.

Table 2. Results from model verification

\begin{tabular}{|c|c|c|c|c|}
\hline & Target & Output & AE & ARE \\
\hline Mean & 108.472353 & 104.653816 & 7.626058 & 0.068242 \\
\hline Std Dev & 40.76889 & 33.526889 & 8.36618 & 0.053997 \\
\hline \multicolumn{5}{|c|}{ Correlation: 0.977641 } \\
\hline
\end{tabular}

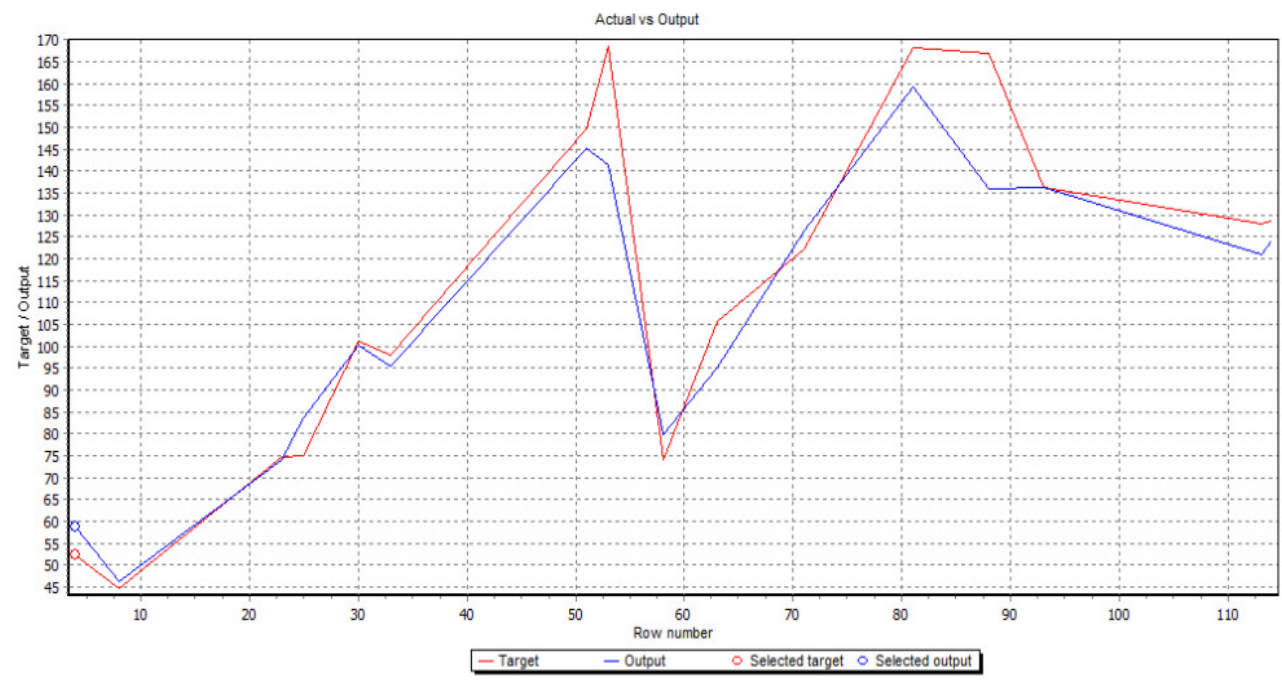

Figure 6. Trend chart of model verification 


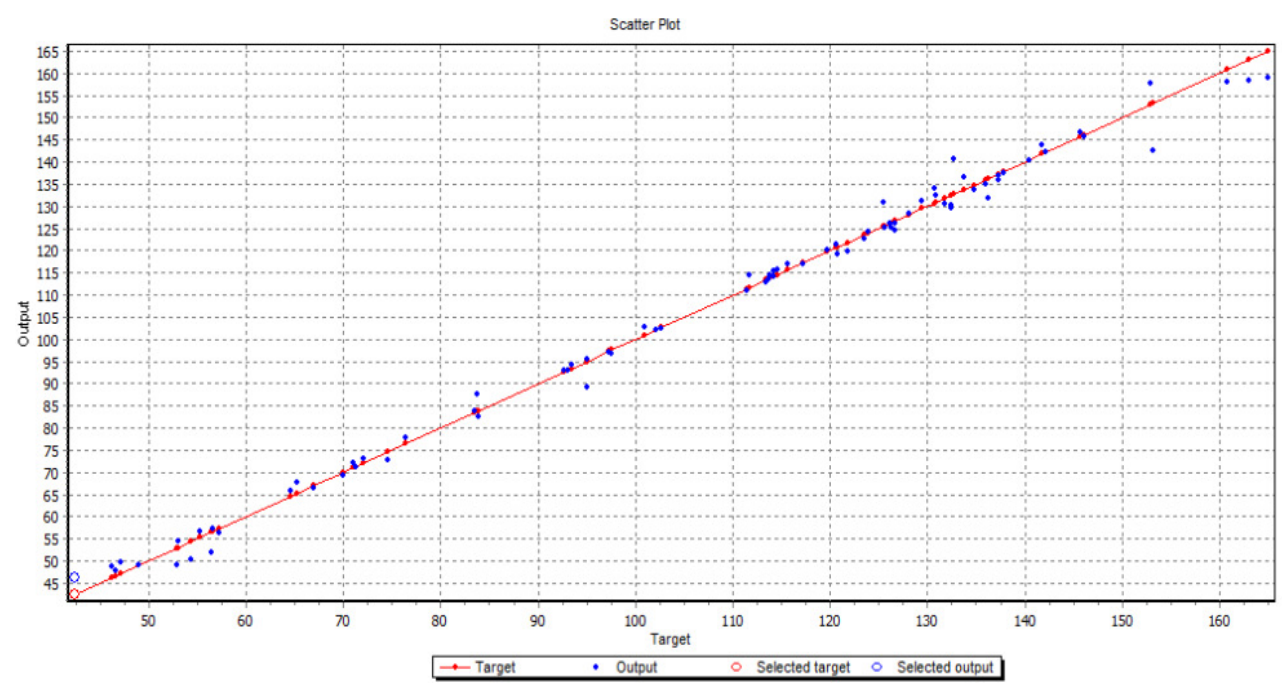

Figure 7. Scatter diagram of model verification

The results of model testing are as shown in Table 3. The output value and actual value of the model are ARE $=9.0058 \%$ and $\mathrm{r}=0.996878$, indicating the model has low error and high correlation. Figures 8 and 9 are the trend chart and scatter diagram of the model input value and actual value. It can be found that input value can reflect the fluctuation of actual value, and has high correlation.

Table 3. Results from model testing

\begin{tabular}{|c|c|c|c|c|}
\hline & Target & Output & AE & ARE \\
\hline Mean & 119.123529 & 117.29254 & 9.87264 & 0.090058 \\
\hline Std Dev & 36.33083 & 35.617172 & 7.116143 & 0.070703 \\
\hline \multicolumn{5}{|c|}{ Correlation: 0.944263} \\
\hline
\end{tabular}

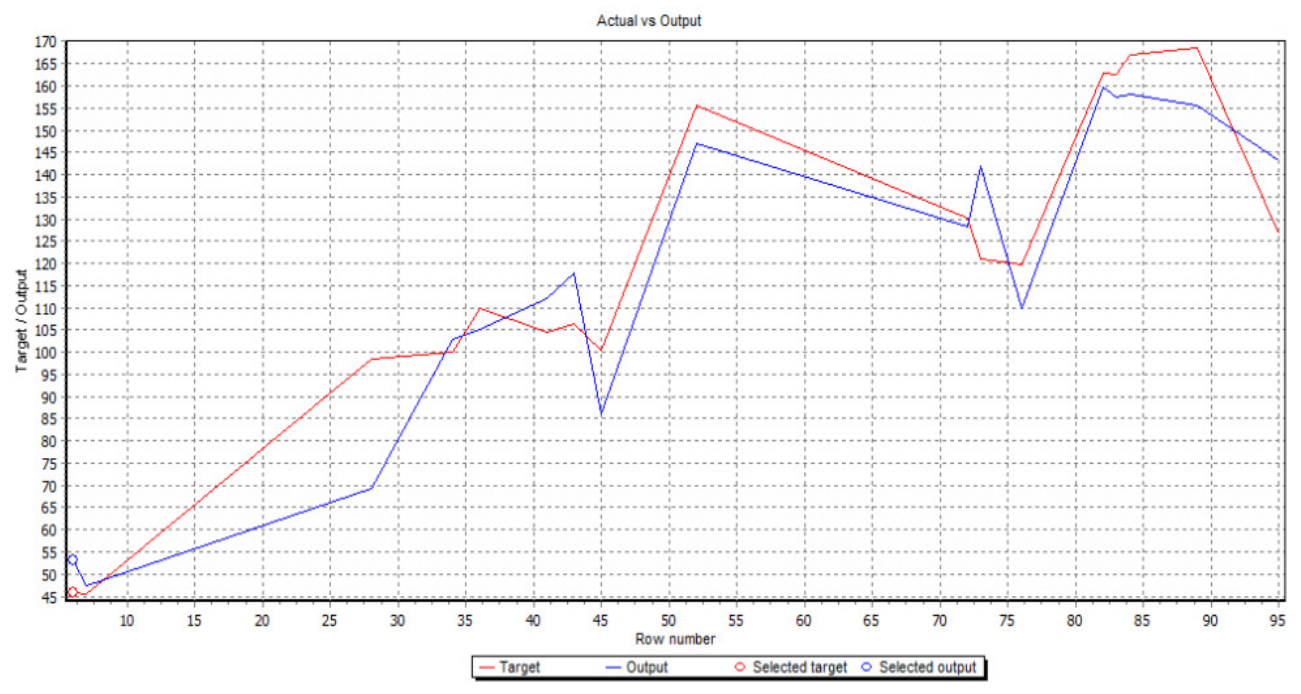

Figure 8. Trend chart of model testing 


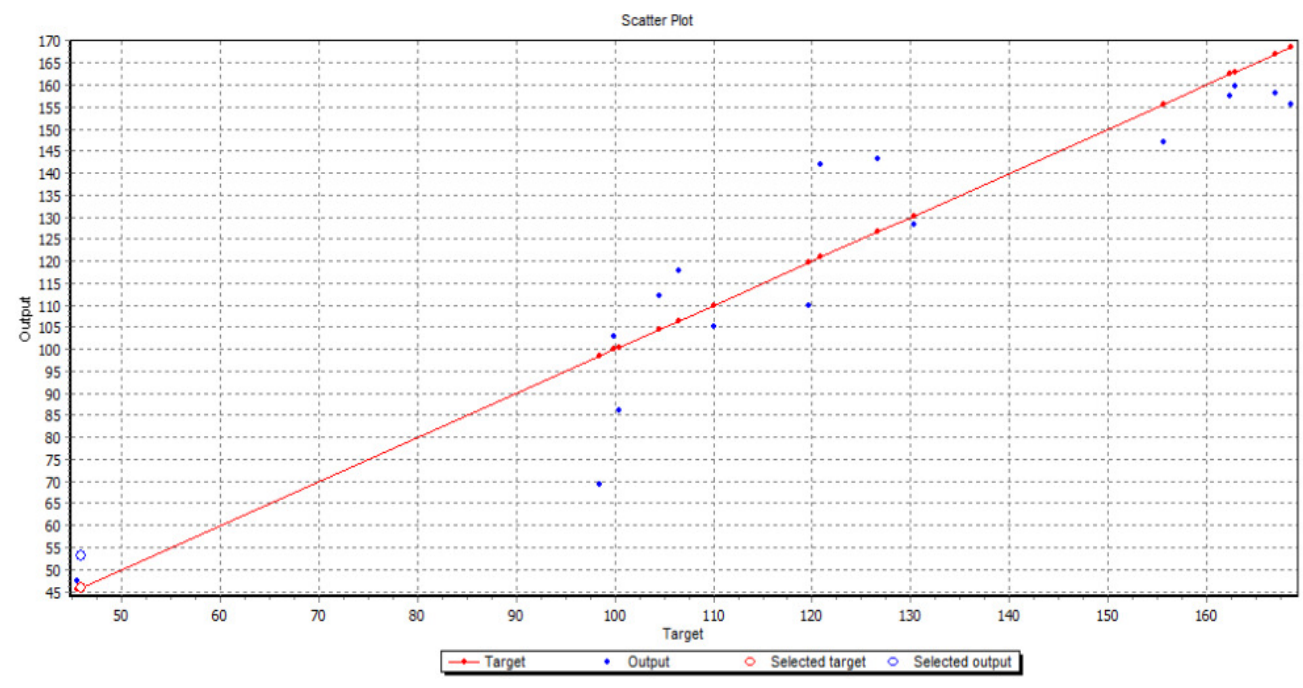

Figure 9. Scatter diagram of model testing

\section{CONCLUSIONS}

This study used BPN to establish a model for predicting the monthly tourism industry stock index. Moreover, the 29 input variables, such as international exchange rate, indices of international stock markets, indicators of Taiwan stock market technical analysis, and overall economic indicator, are used to predict Taiwan's monthly tourism industry stock index. The BPN has better prediction accuracy, ARE is $9.8058 \%$, and correlation is 0.944263 , which indicates the model has low error and high correlation. The model can accurately predicate trends and index changes. The findings can serve as reference for future study or investors.

\section{REFERENCES}

[1] Zou, H.W., \& Tang, B.Y., (2004) "Theoretic Models and Empirical Analysis of Stock Prices Volatility", Journal of Natural Science of Heilongiiang University, Vol. 21, No. 3, pp. 49-53.

[2] Ivanovic, Z., Bogdan, S., \& Baresa, S., (2013) "Strategy of Stock Valuation by Fundamental analysis", UTMS Journal of Economics, Vol. 4, No. 1, pp. 45-51.

[3] Raeia, R., Mohammadia, S., \& Tajik, M.M., (2011) "An Intelligent Technical Analysis Using Neural Network”, Management Science Letters, Vol. 1, No. 3, pp. 355-362.

[4] B. Martinovic, "Stock market prediction using technical analysis", Economic Annals, Vol. 51, No. 170, pp. 125-146, 2006.

[5] Chang, Y.W., (2013) “An Improved Artificial Neural Network Model for Stock Price Forecasting”, Journal of National Taipei College of Business, No. 23, pp. 1-18.

[6] Mantri, J.K., Nayak, B.B., \& Nayak, B.B., (2012) "Design Neural Network for Stock Market Volatility: Accuracy Measurement”, International Journal of Computer Technology and Applications, Vol. 3, No. 1, pp. 242-250.

[7] Nair, B.B., Mohandas, V.P., \& Sakthivel, N.R., (2010) "A Genetic Algorithm Optimized Decision Tree-SVM based Stock Market Trend Prediction System”, International Journal on Computer Science and Engineering, Vol. 2, No. 2, pp. 9.

[8] Tehrani, R. \& Khodayar, F., (2010) "Optimization of the Artificial Neural Networks Using Ant Colony Algorithm to Predict the Variation of Stock Price Index”, Journal of Applied Sciences, Vol. 10, No. 3, pp. 221-225.

[9] Yeh, Y.C., (2009) Artificial Neural Network Application and Implementation, Taipei City: Scholars Books.

[10] Yiin, A., (2005) SQL Server 2005 Data Mining, Taipei City: Delight press. 
International Journal of Computer Science \& Information Technology (IJCSIT) Vol 5, No 6, December 2013

[11] Chang, F.C. \& Chang, L. C., (2005) Artificial Neural Network, Taipei City: Tung Hua Books.

[12] Jiang, X.F., (2013) “An Effective Decision Support System based on Neural Networks and Its Application”, International Journal of Advancements in Computing Technology, Vol. 5, No. 1, pp. $37-45$.

[13] Zhang, J., Chen, Y., Zhao, H., \& Lu, X., (2013) "Novel Calculation Method of Man-hour Quota Based on Parts Similarity and Neural Networks", International Journal of Digital Content Technology and its Applications, Vol. 7, No. 1, pp. 469-476.

[14] Hu, D., (2013) “A Method of Identifying Enterprises' Core Competencies Based on Artificial Neural Network”, Advances in Information Sciences and Service Sciences, Vol. 5, No. 2, pp. 168-176. 